\title{
APPLICATION OF SEVERITY ASSESSMENT TOOL (SAT) TO 2008 MIDWEST FLOOD AFFECTED AREAS
}

\author{
A. DESHMUKH, E. HO OH \& M. HASTAK \\ Division of Construction Engineering and Management, Purdue University, USA.
}

\begin{abstract}
Critical infrastructure provides services to help support activities and functions of communities and industries. These activities/functions contribute socially and economically when performed efficiently in reliance with related critical infrastructure. During disasters, the critical infrastructure gets impacted and is unable to provide the full services which in turn affect the activities depending on that particular infrastructure. This reduces the contribution of the activities which results in impact on communities and industries.

This research provides a unique perspective of preparing cities and industries against natural disasters in pre-, during and post-disaster situation. It is based on the inter-relationship that exists between communities, industries and related critical infrastructure. Identifying and fortifying infrastructure ahead of time will protect and support not only people and properties but also industrial activities and services. Moreover, it will become easier for governmental and industrial organizations to prepare mitigation plans and strategies that would help to prepare, prevent, respond, and recover from potential natural disasters. Thus, public agencies, industries and communities can largely benefit from natural disaster mitigation strategies that would help to speed up the recovery process as well as provide an effective tool to handle the disaster-related resources. The study presents a severity assessment tool (SAT) for evaluating the social and economic impacts on communities and industries due to disaster impacted infrastructure in the context of a case study of 2008 Midwest Floods in the United States. The case study demonstrates the inter-relationship between infrastructure, communities and industries as well as assessment of impacts if the level of serviceability of infrastructure was to be influenced during/after disaster situations. The results of this case study will help the city managers and emergency response agencies in understanding the social and economic impacts of disasters on infrastructure and the associated industries and communities and will assist them in preparing appropriate disaster mitigation strategies.
\end{abstract}

Keywords: critical infrastructure, disaster risk reduction, floods, severity, social and economic impacts.

\section{INTRODUCTION}

Disasters not only result in physical damage in a region but also lead to short-term and longterm social and economic losses. Moreover, such losses are escalated because the critical infrastructure in the affected region fails to function and therefore fails to offer their services that are required to support the communities and industries and also the recovery efforts soon after.

Disasters like Hurricane Katrina in 2005 or the Midwest floods in the United States in 2008 have emphasized the fact that the infrastructure acts as a lifeline and a protector of any affected region in pre-/post-disaster situations.

Since last century, the frequency of extreme hydrological events such as flash floods, seasonal floods, rainfall and snowfall has increased which represents a significant risk to cities not only in developed countries but also in developing countries [1]. Extreme floods bring along with them not only physical damage but also indirect impact on communities and industries as social and economic impacts [2-4].

The national cost of natural disasters in United States has risen up to $\$ 100$ billion in 2005 [5]. In 2005, the city of New Orleans was devastated by Hurricane Katrina. It was suggested that 
the losses were escalated due to loopholes in federal, state and local policies for disaster preparedness that led to an overall loss of $\$ 96$ billion in housing, food, oil, electricity, etc. [5]. Experts suggest that a lack of preparedness, improper disaster mitigation plans and poorly maintained infrastructure are a few of the many reasons that led to an increase in the impact of Hurricane Katrina on the United States.

Therefore, the purpose of this research is to assess the social and economic impacts on communities and industries due to reduced serviceability level of related flood damaged critical infrastructure.

A review of prior research work was conducted to understand and develop the interrelationship that exists between infrastructure and depending communities and industries.

The Federal Emergency Management Agency (FEMA) has developed a GIS integrated tool, HAZUS-MH that helps emergency officials to estimate social and economic losses on communities. Currently HAZUS-MH is developed to estimate losses for earthquake, floods, and hurricanes. Potential loss estimates analyzed in HAZUS-MH provides information in three different types, i.e. physical damage to residential and commercial buildings, economic loss in terms of lost jobs, business interruptions, repair and reconstruction costs; and social impacts, including estimates of shelter requirements, displaced households, and population exposed to disasters. Furthermore, the model also helps in debris generation and shelter requirements [6].

Rapid response to recovery after any disaster is improvised by available infrastructure. For example, damaged but still serviceable routes might become evacuation routes or might help speed up the logistics of providing relief supplies. Furthermore, if infrastructure is quickly restored, it can help the depending communities and industries revive from the aftermath of the disaster. HAZUS-MH does not provide information on the inter-relationship between infrastructure, communities and industries which would be helpful in preparing better mitigation strategies. Due to this limitation, experts may have difficulties to find the most appropriate methods at the right time to temporarily mitigate the impacts [4].

\section{CONCEPTUAL FRAMEWORK FOR ASSESSING FLOW OF DISASTER IMPACT FROM INFRASTRUCTURE TO COMMUNITIES AND INDUSTRIES}

Oh et al. $[7,8]$ proposed a basic cell model of disaster impact mechanism to analyze the flow of impact of natural disasters on infrastructure, communities and industries. Similarly, Hiete et al. [9] have proposed a framework to assess the vulnerability of industrial sectors towards disaster losses. The framework suggests that a failure of infrastructure will impact functions of industries such as production, manufacturing, etc., which results in economic losses. Relationships exist between critical infrastructure and communities and industries which get impacted due to disasters.

However, the defined relationship addresses technical issues only which needs to be further extended to include social and economic issues as well.

Oh et al. [4] proposed a Decision Support System which explains assessment of flood impacts on communities and industries based on the technical, social and economic data collected from site.

2.1 Data collection - NSF SGER: a short-term site investigation of 2008 midwest floods

The data collection efforts for the study were supported by the National Science Foundation (NSF) SGER: a short-term site investigation of 2008 midwest floods (Award\# 0848016). 
During the NSF SGER project, the research team focused on critical infrastructure and the impacts on associated industries and communities through damaged critical infrastructure. Timing of data collection was very important for ephemeral data; however, it was also true that additional relevant data was obtained from interviews and survey questionnaires due to limited accessibility to the affected areas after the occurrence of floods.

Data collection from the affected areas was conducted through interviews, survey, and site-investigations. The collected data included:

- Critical infrastructure (roads, bridges, wastewater treatment plants, etc.).

- Affected infrastructure (locations, reported damages, adjacent facilities, industrial activities or services that rely on the affected infrastructure, etc.).

- The level of damage of infrastructure, the period of service failure, and description of details.

- Main functions and services that were disrupted for specific industries in the affected area (industrial zoning map, distribution center, corporation office, manufacturing, retail center, warehouse, etc.).

- Demographical information (i.e. population, gender, employment, income, etc.)

\section{Interviews}

- Fifteen interviews in Cedar Rapids (the city departments (7), industrial parties (4), community parties (4)).

- Six interviews in Terre Haute, Gulfport, and St. Louis.

\section{Survey Questionnaires}

Sixty-five complete questionnaires were collected from affected communities in the City of Cedar Rapids.

Some of the results of the survey are illustrated. Respondents were asked to identify utility infrastructure. Bridges and roads were rated as the most important infrastructure in Cedar Rapids for the communities to sustain their lives.

Damaged infrastructure had a huge impact on people's life. It was difficult for people to commute, maintain social relationships, etc. Respondents were asked about impact of damaged infrastructure on their daily activities. Five activities, i.e. purchasing basic items, increased travel time, access to family, access to friends and others were listed. The participants were asked about the inconvenience that they experienced in performing daily activities, purchasing basic commodities, effect on travel time and whether the participant could interact with family and friends after the floods (Fig. 1).

Based on the above research, Deshmukh et al. [11] proposed a conceptual framework to understand the flow of impact from infrastructure to industries and communities. The framework establishes a relationship between infrastructure, communities and industries which is based on the fact that activities and services of communities and industries are sustained by services offered by critical infrastructure.

The flow of impact of a natural disaster on infrastructure and communities and industries can be classified as primary impact which leads to physical damage on communities, industries and infrastructure. The primary impact leads to a reduction or failure of services of critical infrastructure.

Primary impacts usually occur during the disaster events, physically damaging the critical infrastructure which influences the social and economic assistance offered to the activities of 


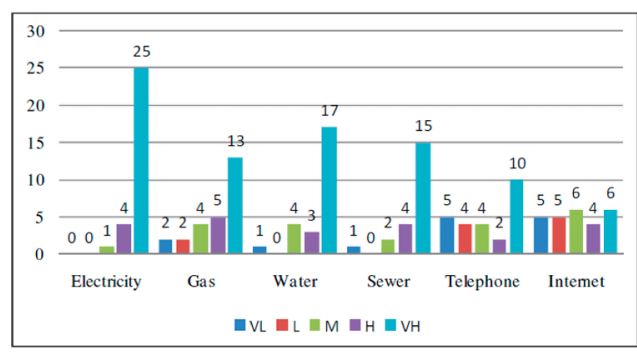

Critical Infrastructure ratings based on importance level

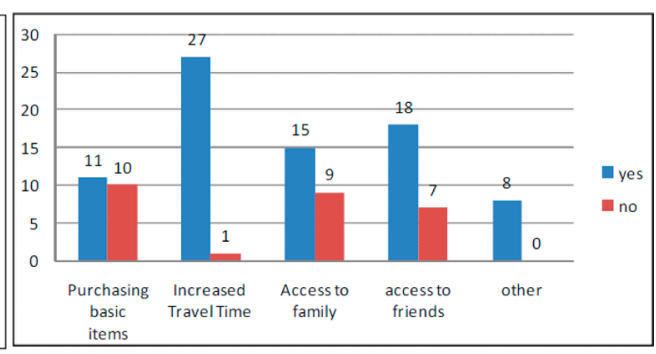

Effect of damaged infrastructure on personal life

Figure 1: Survey response [10].

communities and industries in the form of benefits. Reduction in these benefits results in social and economic impacts. Social and economic impacts can be defined as:

- Social Impact: Reduction in social contribution offered by activity/function of communities and industries due to failure of services of critical infrastructure in terms of social aspects, i.e. social surroundings of an individual or a family.

- Economic Impact: Reduction in economic contribution offered by activity/function of communities due to failure of services of critical infrastructure in terms of economic aspects.

In case of a disaster event such as flood, the activities will get impacted indirectly due to failure of services of related critical infrastructure. The services offered by critical infrastructure reduce to a certain level of serviceability. As a result, the activities will have a reduction in the social and economic benefits offered by such critical infrastructure. This reduction in benefits for communities and industries due to reduced level of serviceability of critical infrastructure can be assessed as social and economic impacts due to disaster events. Social and economic impact assessment for communities and industries can be made if:

- Serviceability level of the related critical infrastructure is known after a disaster.

- A relationship between social and economic benefits for activities of communities and industries and serviceability level of related critical infrastructure can be established.

\subsection{Severity assessment}

Severity assessment will be conducted based on the reduced serviceability of critical infrastructure. Activities will be used as impact measurement factors for performance assessment of damaged critical infrastructure.

- Definition: Severity implies the extent of social/economic impact (loss of contribution) of activities associated with industries and communities that get affected by critical infrastructure damaged by natural disasters.

- Need: The severity assessment module establishes the technical, social and economic impacts due to the natural disaster (i.e. floods) under the criticality and vulnerability conditions established earlier. 
- Approach and Expected Results: Since the level of dependence on critical infrastructure would vary for different social and economic activities, the resulting impact (severity) due to a disaster event is also going to vary based on the various levels of vulnerability determined.

The assumption for severity assessment is that social and economic impacts on communities and industries due to damaged infrastructure are proportional to the reduction in serviceability level of that infrastructure.

Figure 2 shows a framework for severity assessment on communities and industries due to flood impact. The framework uses a web-based Analytic Hierarchy Process (AHP) tool developed by the research team for prioritization of activities for their contribution and infrastructure for their assistance level towards supporting activities. Simulation is performed using Monte Carlo simulation technique using excel spreadsheets. Frequency diagrams are generated using simulation to represent social and economic impacts graphically. In the webbased tool designed for this research, activities are rated using a scale ranging from 1 to 9 , where 1 is least important and 9 is most important for rating economic contribution offered by activities.

Critical infrastructure is damaged by the flood impacts which affect their serviceability level. Serviceability level can be assessed using its vulnerability level towards flood impacts. For this research, vulnerability has been defined as threats or real hazards to infrastructure, industries or communities in disaster situations that can vary according to the conditions of infrastructure [8]. The level of vulnerability is measured in terms of probability as the vulnerability of critical infrastructure against floods based on the infrastructure health (State of Good Repair), its characteristics and flood level. This implies that an infrastructure having a high vulnerability level is likely to achieve a low level of serviceability after a flood impact and vice versa.

A brief explanation of the concept is provided by application of the tool to a real case study.

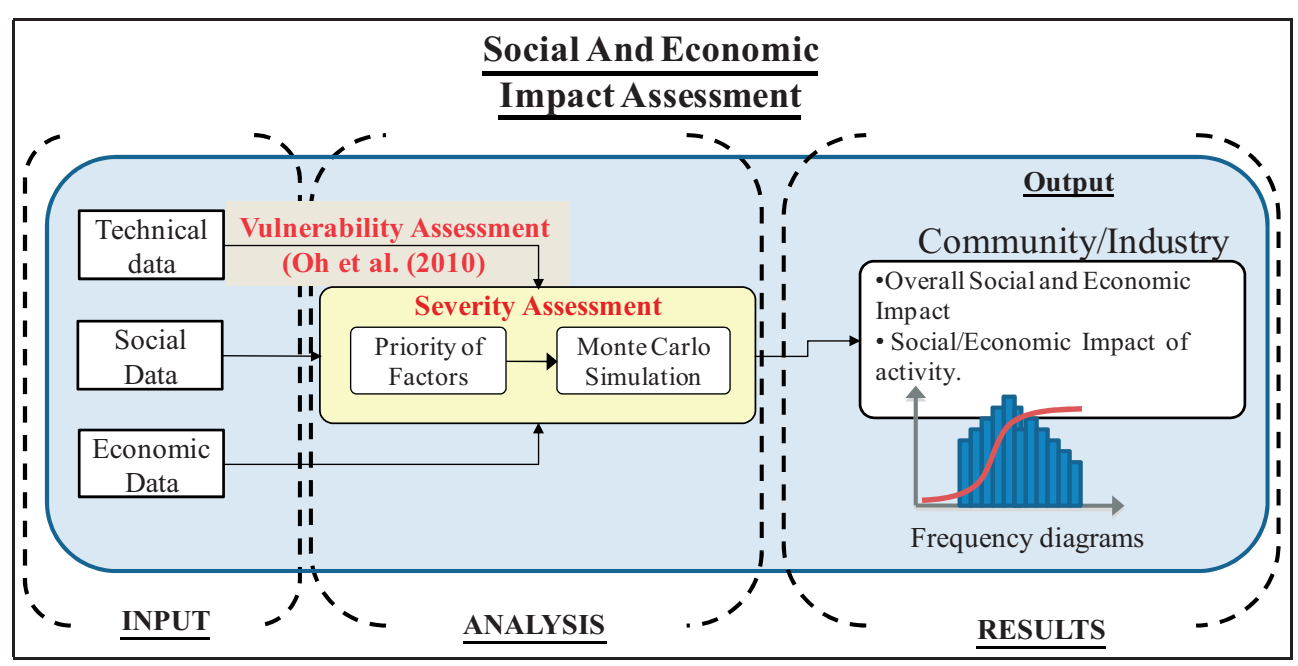

Figure 2: Social and economic impact assessment (severity assessment), [11]. 


\section{SEVERITY ASSESSMENT FOR 2008 MIDWEST FLOODS DISASTER AFFECTED AREA}

The proposed framework is explained through a case study where an industry in a town is impacted by a flood event. Relevant data were collected from Cedar Rapids, Iowa, which was devastated by 2008 Midwest Floods.

\subsection{Introduction to case study - 2008 Midwest floods}

Cedar Rapids, Iowa, was selected for model application mainly because of the following reasons:

- The city experienced major flooding which affected both the communities and industries. Many residential neighborhoods were completely inundated which led to displacement of population, closure of local businesses and huge property and personal losses.

- The impact was escalated due to the failure of critical infrastructure in the geographical location.

- In 1993, the city had witnessed major flooding after which, the design of several flood protection systems were modified and renovated to withstand the 500 year flood in the affected area. However, 2008 Midwest floods exceeded the 500 year flood conditions and offered an opportunity to study the role played by critical infrastructure in Cedar Rapids in pre-, during and post-flood situation (Fig. 3).

The SAT will be applied to an industry, Diamond V located in Cedar Rapids, Iowa. It is a global enterprise which supplies feed ingredients to yeast manufacturers. The industry was completely shut down during 2008 Midwest floods. A survey was conducted to apply SAT for economic impact assessment.

\subsubsection{Step 1: Identification of activities and establishment of relationship between related critical infrastructure and Diamond V industry}

With the help of Diamond V officials, the major activities of Diamond V which make an economic contribution to their business were identified. The following activities were considered economically important, i.e. administration, manufacturing, raw material (procurement), warehousing, finance, shipping, commuting.

\subsubsection{Step 2: Prioritization of activities}

However, not all the activities were considered as equally important. Manufacturing and raw material (procurement) were identified as important economic activities. AHP was used for activity prioritization based on the level of contribution made by each activity in terms of economic aspect.

AHP of severity assessment is equipped with a web-based tool for prioritization of activities and infrastructure. AHP establishes a priority vector by using matrix computations to determine the eigen vector corresponding to the maximum eigen value $[12,13]$. The method includes consistency check to minimize errors due to biased ratings, overrated or underrated scores, etc. In the web-based tool designed for this research, activities are rated using a scale ranging from 1 to 9 , where 1 is least important and 9 is most important for rating social and economic contributions offered by activities/functions to the communities and industry.

The same feature was used for calculating the prioritization of activities (Fig. 4). For instance, 'A1' represents activity 'administration' and 'A2' represents activity 'raw material 


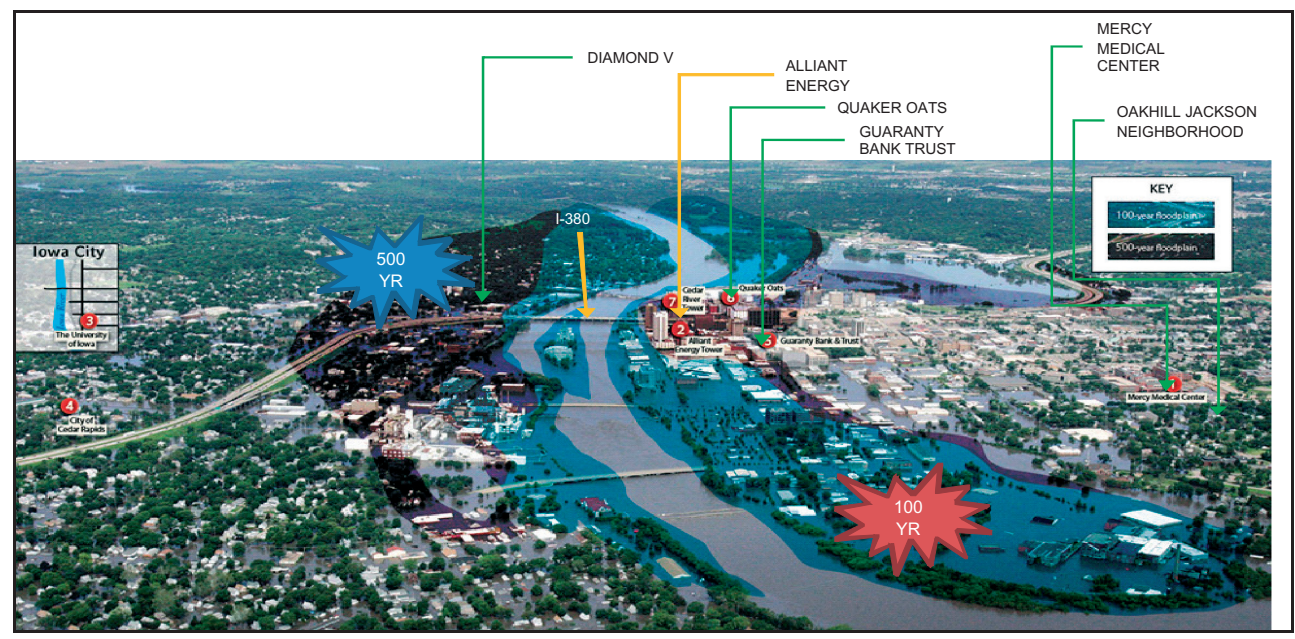

Figure 3: Flooded Cedar Rapids, Iowa. Source: Courtesy www.buildings.com, June 2008.

\begin{tabular}{|c|c|c|c|c|c|}
\hline \multicolumn{6}{|l|}{ Criteria Items Criteria Evaluation } \\
\hline \multirow{3}{*}{$\begin{array}{l}\text { A1 : Administration } \\
\text { A2 : Raw Material (Procurement) } \\
\text { A3 : Manufacturing }\end{array}$} & & & \multirow{3}{*}{\multicolumn{2}{|c|}{$\begin{array}{l}\text { A4 : Warehousing } \\
\text { A5: Shipping } \\
\text { A6 : Finance }\end{array}$}} & \multirow{3}{*}{ A7 : Commuting } \\
\hline & & & & & \\
\hline & & & & & \\
\hline \multirow{9}{*}{ Start from here : } & & A1 & A2 & $\mathrm{A} 4$ & A6 \\
\hline & A1 & 1.0 & $1 / 4=$ & $1 / 8=\sqrt{6} \quad$ & $1 / 2=\longdiv { 2 } = \sqrt { 3 } =$ \\
\hline & A2 & & 1.0 & 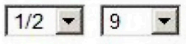 & $\mid \begin{array}{llll}2 & \sqsupset & 5 & \nabla\end{array}$ \\
\hline & A3 & & & $\begin{array}{lll}1.0 & 9\end{array}$ & $\mid \begin{array}{llll}2 & \sqsupset & 7 & 7\end{array}$ \\
\hline & A4 & & & 1.0 & 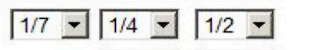 \\
\hline & A5 & & & & $\begin{array}{llll}1.0 & \square & \square\end{array}$ \\
\hline & A6 & & & & $1 . 0 \longdiv { 2 }$ \\
\hline & A7 & & & & 1.0 \\
\hline & & Consis & ency Ratio & 0.04 & \\
\hline
\end{tabular}

Figure 4: Activity prioritization using web-based AHP for Diamond V.

(procurement)'. In this pairwise comparison, 'administration' is given a score of (1/4) when compared with 'raw material (procurement)' based on the level of economic contribution they make for the industry. A similar pairwise comparison is made between each activity. Once, the scores are provided, the module is run and checked for consistency (Fig. 4). It was observed that the provided ratings for each activity were consistent thereby minimizing bias.

Table 1 shows the results obtained from AHP analysis. Manufacturing and raw material were found to be activities making the most economic contribution. Shipping and raw material (procurement) were also found to be economically important. 
Table 1: AHP scores for activities.

\begin{tabular}{|c|c|c|c|c|c|c|c|}
\hline Activities & $\begin{array}{l}\text { Admin- } \\
\text { istration }\end{array}$ & $\begin{array}{c}\text { Raw } \\
\text { material } \\
\text { (procurement) }\end{array}$ & $\begin{array}{l}\text { Manu- } \\
\text { facturing }\end{array}$ & $\begin{array}{l}\text { Ware- } \\
\text { housing }\end{array}$ & $\begin{array}{l}\text { Ship- } \\
\text { ping }\end{array}$ & Finance & $\begin{array}{l}\text { Commu- } \\
\text { ting }\end{array}$ \\
\hline $\begin{array}{l}\text { Eco } \\
\text { contribution }\end{array}$ & 0.089 & 0.249 & 0.366 & 0.023 & 0.183 & 0.066 & 0.034 \\
\hline
\end{tabular}

\subsubsection{Step 3: Identification of related critical infrastructure}

Diamond V's corporate office is located near an interstate highway I-380 exit 19B and is very close to the river. Through the interview, the following infrastructure were identified as critical that supported the activities of Diamond V, i.e. electricity (Alliant Energy), water Supply (City water distribution), sewer, gas, telecommunications, transportation (includes major routes such as FH 151, I-380 and local routes such as 3rd St, etc.), postal Services. It was observed that:

- Infrastructure alternates were available for shipping and commuting.

- Electricity, water supply, sewer, gas, telecommunications and postal services did not have any alternates to support depending activities.

Moreover, activities that depend on these infrastructure such as administration, manufacturing, warehousing, finance, raw material procurement required serviceability of each infrastructure at the same time. This means that in any given situation, the related critical infrastructure with minimum serviceability level would govern the economic impact.

The infrastructure supporting Diamond V such as roads, bridges, electricity, etc. are protected by a nearby levee system. During the 2008 floods, the levee system had failed leading to the failure of related critical infrastructure. Figure 5 shows related critical infrastructure supporting various activities of Diamond V.

In this research, it is assumed that the serviceability available before the disaster is considered as the benchmark, i.e. $100 \%$ serviceability of that infrastructure.

The ingredient manufactured by Diamond V needs raw material that is supplied by local as well as regional suppliers. Therefore, shipping is important for not only acquiring raw material but also shipping the manufactured product. As shown in Fig. 5, shipping is supported by various local and state roads. However, the level of assistance provided by each infrastructure or combination of infrastructure will vary. This is likely based on the physical characteristics of roads such as speed limit, type of pavement, traffic volume, etc.

Such parameters influence the choice of taking a particular route. It was observed that many routes were short and for the simplicity purpose of this example, the routes were combined together to form one combined infrastructure alternate.

\subsubsection{Step 4: Application of severity assessment tool (SAT)}

\subsubsection{Prioritization of infrastructure alternates (pre-disaster situation)}

In this example, assessment of economic impact on activity 'shipping' is explained using SAT. As shown in Fig. 5, activity shipping can be performed using six routes in pre-flood situation. Even though the existing physical condition of infrastructure alternates may be 


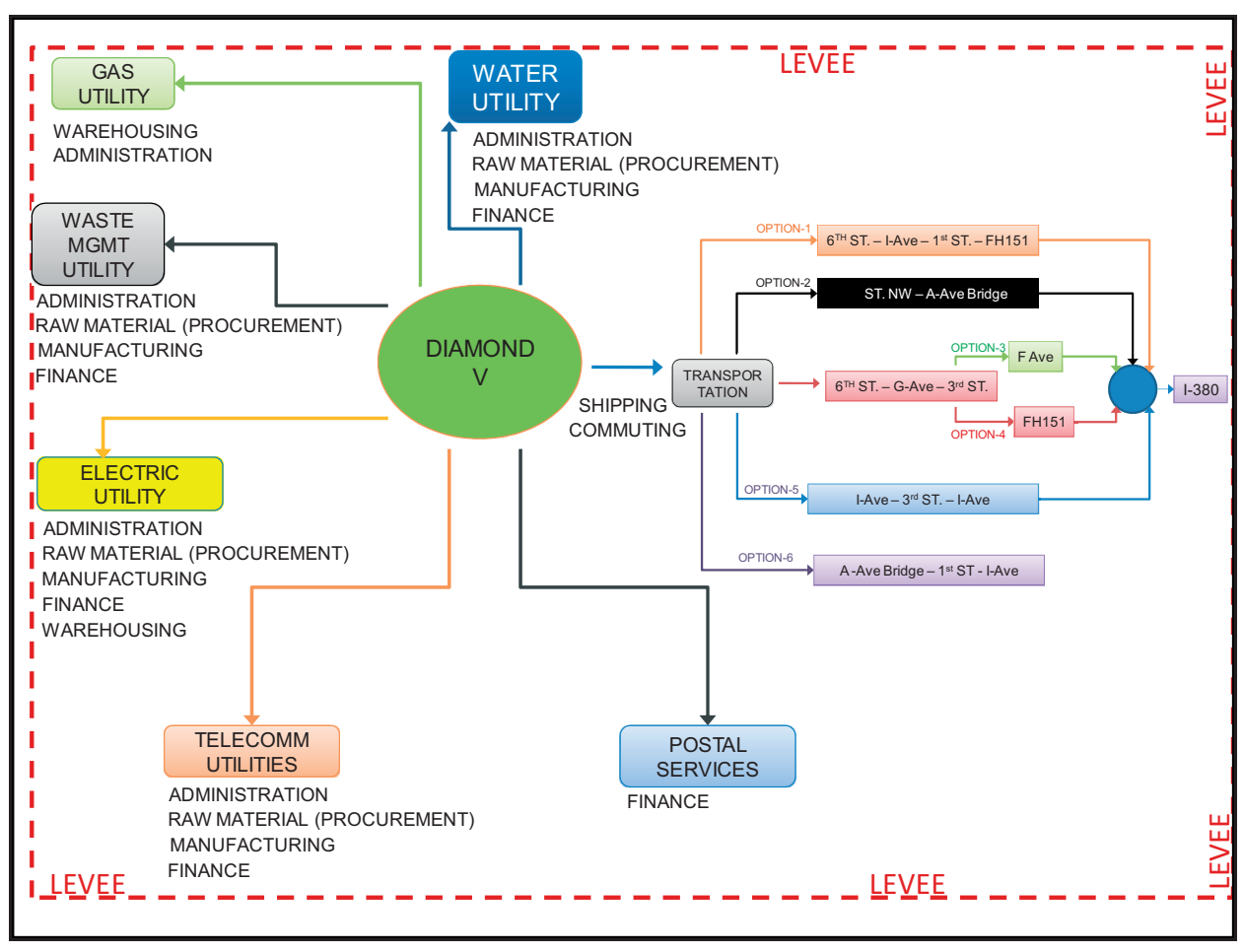

Figure 5: Critical infrastructure supporting activities of Diamond V.

different they are still able to support shipping. This difference in physical conditions and other attributes will influence the assistance level provided by each infrastructure.

Based on this approach, the interview respondent rated infrastructure alternate (Fig. 6). Option 3, i.e. 6th St. - G Ave - 3rd St. - F Ave - I-380 was found to provide the maximum assistance level when compared with other alternatives. AHP analysis was used to rank the infrastructure alternates (Fig. 7). The ratings thus obtained were normalized with respect to the best score (Fig. 7).

The highest economic assistance available to activity 'shipping' will be the best economic assistance option offered in a pre-flood situation among the infrastructure options available. Therefore, the 'best' infrastructure option will help in sustaining depending activity at maximum economic assistance in any give situation. Option 3 provides $100 \%$ economic assistance (which is the maximum assistance offered to support activity 'shipping'). Thus, when option 3 is used for supporting shipping, it can be expected that shipping will provide $18.3 \%$ economic contribution to the industry (Fig. 7).

It is to note here that, even though option 3 is the best option for sustaining shipping, it is not the only option to support shipping in a pre-flood situation. The other routes are capable of supporting shipping but at an economic assistance level lower than option 3 .

\subsubsection{Assessment of level of serviceability of critical infrastructure}

In post-flood situation, the infrastructure is likely to get impacted by floods. This results in the reduction of their serviceability level. SAT assumes that the economic contribution of supported activity is proportional to the reduction in serviceability level of the related critical 


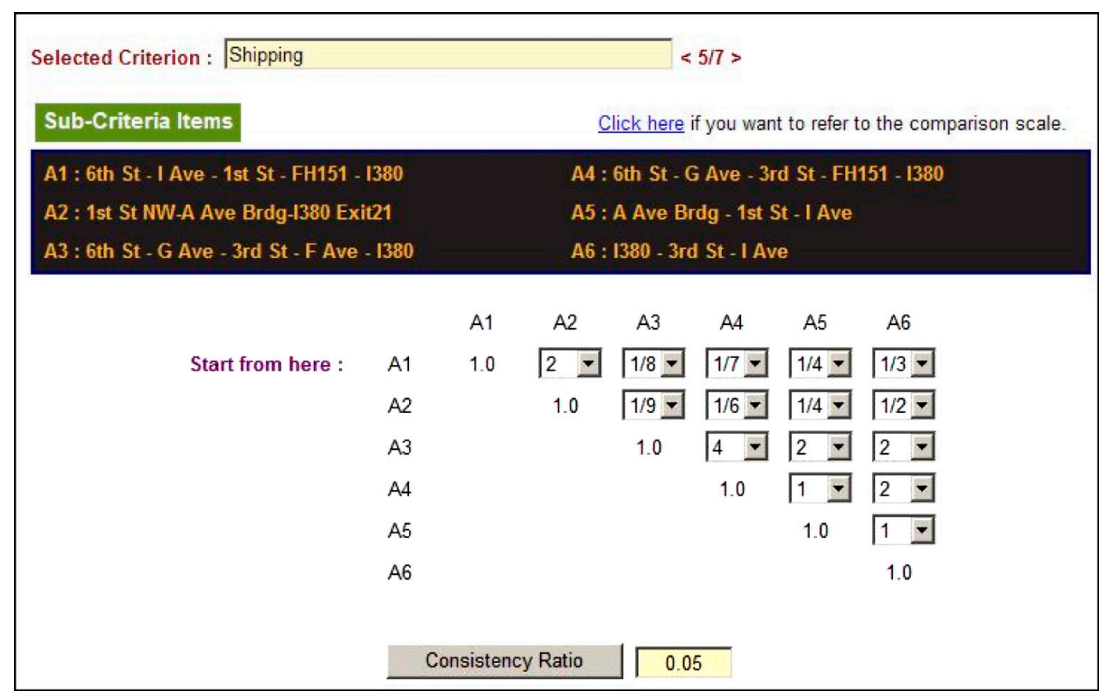

Figure 6: AHP method for ranking infrastructure alternates.

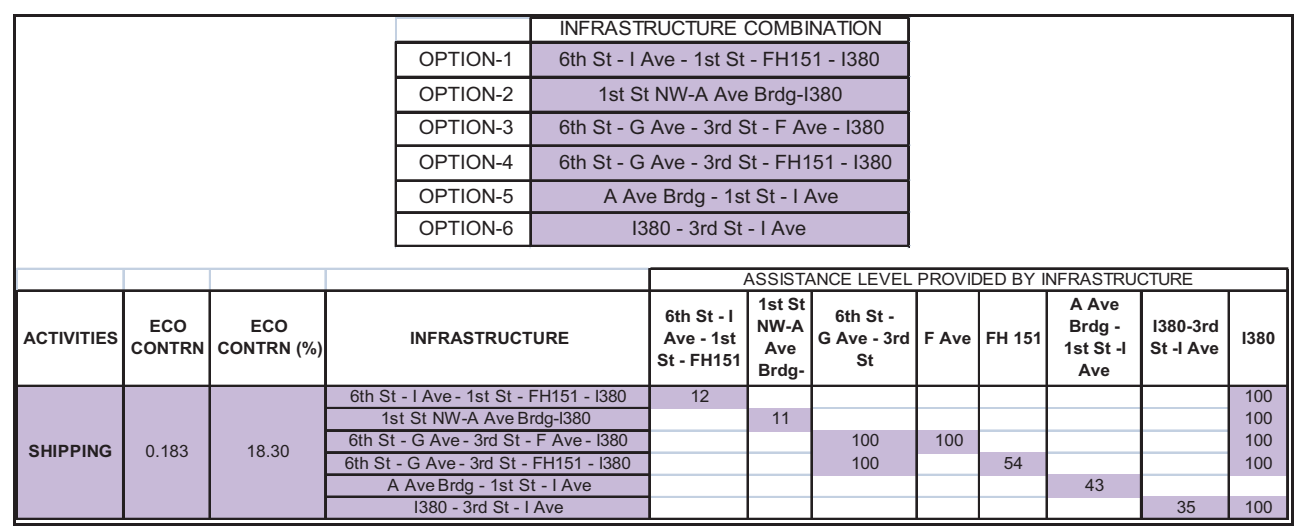

Figure 7: Assistance level provided to infrastructure alternates.

infrastructure. Reduction in economic contribution of activity is assessed under the economic impact.

In this research, it is considered that the level of serviceability is related to the level of vulnerability of an infrastructure towards floods [7]. This means, an infrastructure having a high level of vulnerability is likely to have low level of serviceability after floods. However, it is very difficult to assess the level of serviceability that an infrastructure will achieve after floods.

Therefore, it is considered that the related critical infrastructure will achieve some reduced level of serviceability (Fig. 8). As shown in Fig. 8, each box represents a pre- and post-disaster situation of infrastructure alternates. The serviceability level and social and economic assistance offered by each infrastructure are represented in each box. The dotted lines represent the best infrastructure options available in pre and post-flood situations. The economic impact assessment for activity 'shipping' as shown in Fig. 8 is explained in Table 2. 


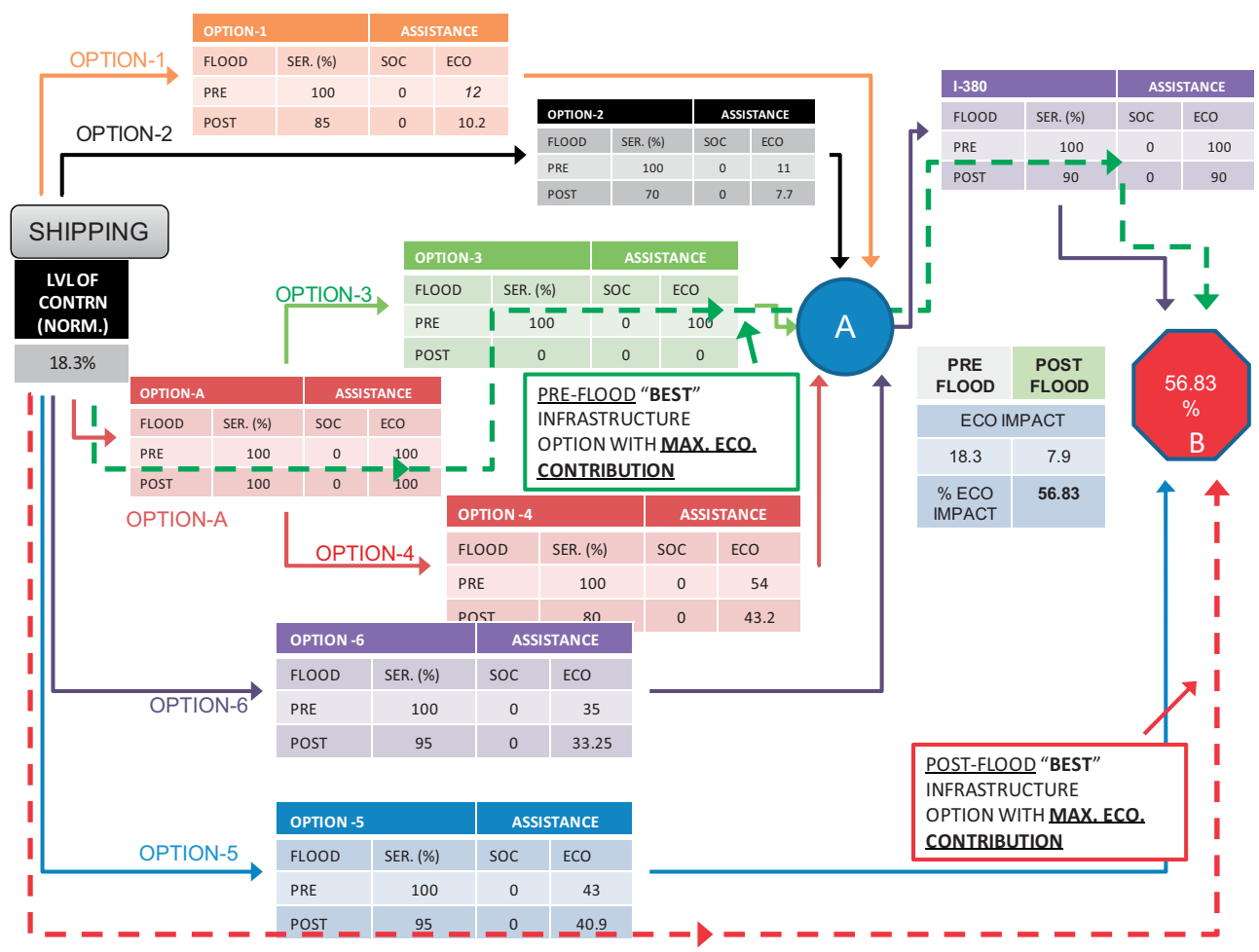

Figure 8: Severity assessment for shipping.

As discussed earlier, the activities contributing economically are prioritized using AHP. It is found that shipping provides $18.3 \%$ economic contribution to Diamond V (col. 1). It is supported by infrastructure alternates (col. 5) and in pre-flood situation, option A - option 3 - I-380 provided the maximum assistance level to support activity 'shipping'.

However, after the floods, the serviceability of infrastructure in the disaster affected area is likely to get reduced. Thus, it is possible that the 'best' infrastructure alternate in pre-flood situation may fail to hold its position. During interview, it was brought to notice that the F-Ave bridge was completely inundated which led to its service failure. In other words, the serviceability level of the aforesaid reduced to $0 \%$ after the floods.

Moreover, all infrastructure alternates experienced a reduction in their serviceability level. This impacted the economic contribution provided by shipping. But, at this juncture, finding the 'best' infrastructure alternate in post-disaster situation is of prime importance as it will help in making decisions for minimizing economic impact on Diamond V.

Table 2 shows the assessment of economic impact for activity shipping and shows calculation for severity assessment as shown in Fig. 7. Separate infrastructure is connected using nodes.

- Option 1-4 and 6 merge at node A and finally connect to I-380 at node B.

- Option 5 directly connects to node B.

Node B marks the completion of activity shipping. The assistance level offered by infrastructure is calculated at each node. The economic assistance is calculated at node A and 


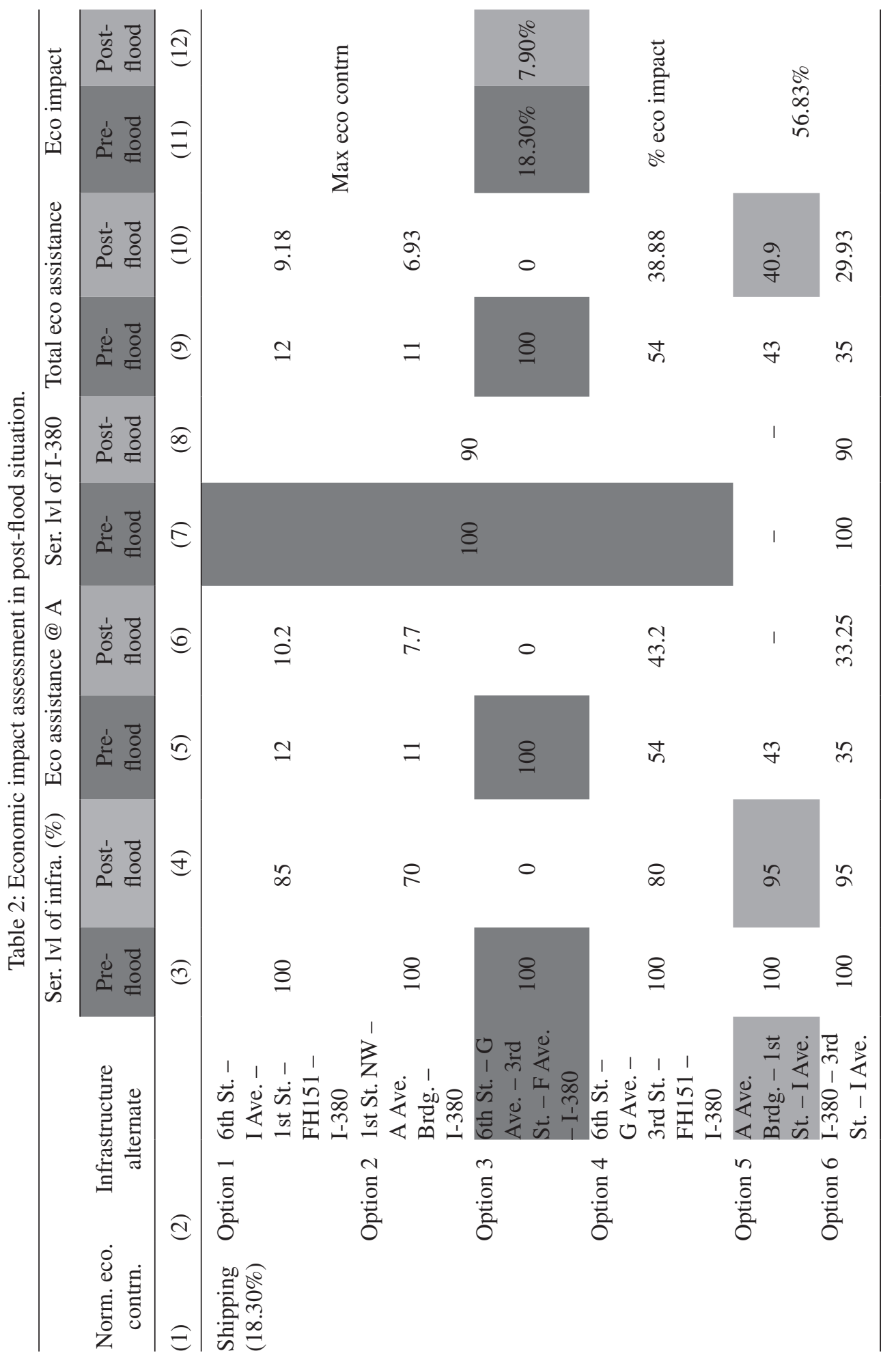


node B. In this example, routes are combined together to act as one infrastructure which finally merge to I-380.

\subsubsection{Economic impact assessment}

In pre-flood situation, option 3 (col. 2, Table 2) provided the maximum economic assistance to activity 'shipping'. Therefore, it can be expected that using option 3, 'shipping' can contribute $18.30 \%$ economically to Diamond V.

In pre-flood situation, economic contribution (col. 7, Table 2) can be calculated as $18.3 \%=$ $18.3 \%$ (col. 1, Table 2) $\times 100 \%$ (col. 3, economic assistance of infrastructure) $\times 100 \%$ (col. 5 , total economic assistance of I-380). The economic contribution offered by 'shipping' (col.-1). The serviceability level was assumed to be $95 \%$ which brought down the economic assistance level to $40.9 \%$ (Table 2). The green highlighted cells represent the best option in pre-disaster situation where as the red highlighted cells indicate the best option in postdisaster situation (refer to online version of the paper for color). Different levels of economic contribution are obtained for pre- and post-flood situation based on which economic impact is calculated $((18.3 \%-7.90 \%) / 18.3 \%=56.83 \%)$.

\subsubsection{Generation of results}

However, the economic impact will vary according to the changing level of serviceability of associated infrastructure. In order to generate results over large range, i.e. $0-100 \%$ of serviceability level of critical infrastructure, Monte Carlo simulation will be helpful [14] .

The changing level of serviceability is obtained as randomly generated numbers from uniform distribution.

Uniform distribution gives equal probability of occurrence to numbers between and including 0-100 which fits well in the statistical analysis. Monte Carlo simulation was performed 1000 times, each cycle providing a unique level of serviceability for the related critical infrastructure. The max economic assistance level obtained from the infrastructure alternate was used for assessing the respective economic impact. Based on this simulation, a frequency diagram was plotted (Fig. 9). From the frequency diagram, it can be read that there is a $59 \%$ probability that the economic impact on shipping will be $67.80 \%$ or less. Similarly, economic impact of different activities was calculated based on the reduced level of serviceability of critical infrastructure (Fig. 9).

\section{CONCLUSION}

Serviceability of critical infrastructure plays an important role in post-flood situation. It can be understood from the above analysis that flood damaged infrastructure lead to inefficient sustenance of supported activities. Most of the activities of Diamond V do not have infrastructure alternates. This issue achieves prime importance when rapid recovery of communities and industries is being worked out. Diamond V pointed out that because the loss due to shut down of activity manufacturing was escalating as there was no electricity, the industry was looking for alternates for getting electricity which did not turn out to be feasible. If severity assessment was conducted prior to the 2008 Midwest floods, it is for sure, the losses could have been minimized.

It was observed that activities like manufacturing and warehousing of Diamond $\mathrm{V}$ rely on more than one different type of infrastructure that do not have a back up. Furthermore, the probability of having a high impact in such cases was higher when compared with impact on activities having more than one similar type of supporting infrastructure. This is due to the fact that, the minimum assistance level of related critical infrastructure influences the impact on activities. 


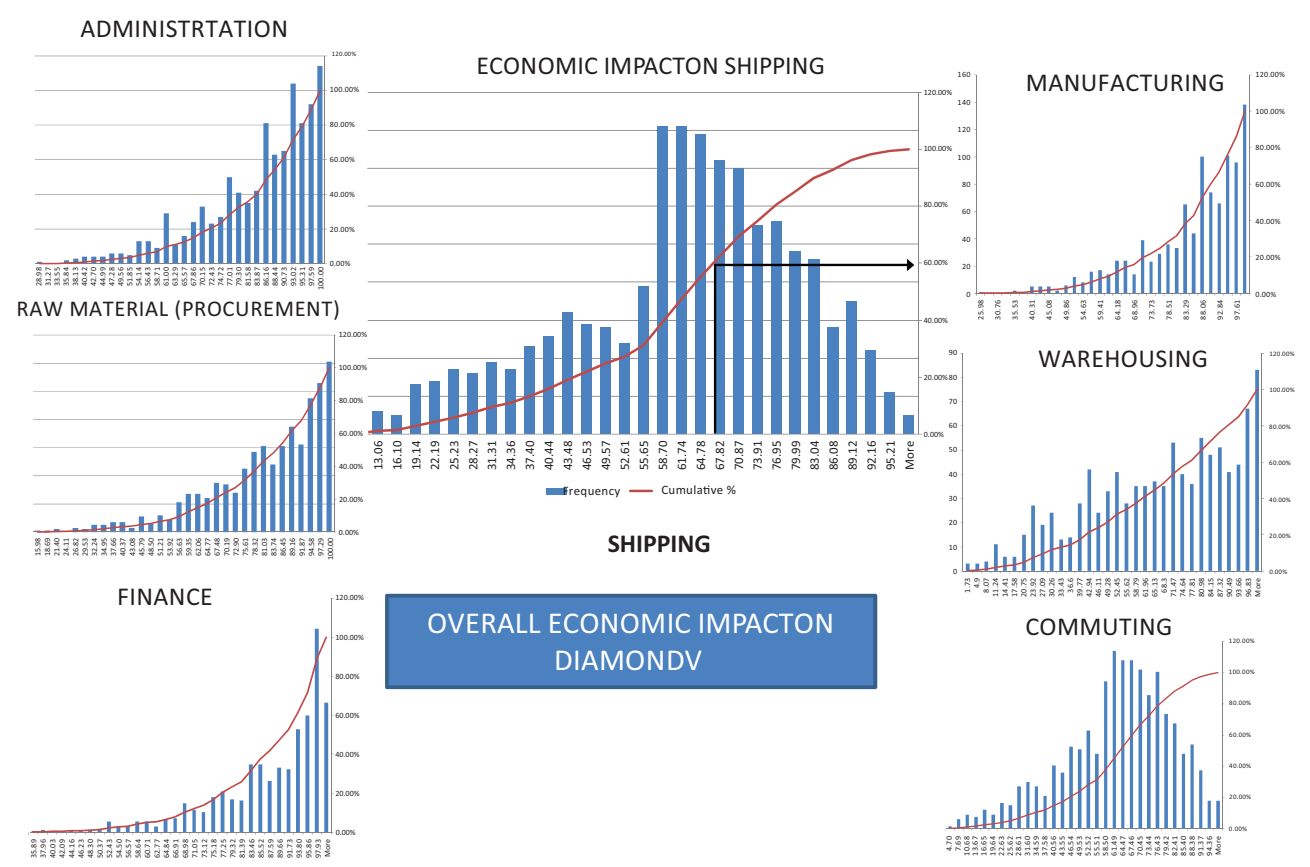

Figure 9: Frequency diagram for economic impact on shipping (economic impact on $\mathrm{X}$ axis, cumulative frequency on $\mathrm{Y}$ axis).

\section{ACKNOWLEDGEMENTS}

Part of the research presented in this paper is based on work supported by the US National Science Foundation under Grant No. 0848016. Any opinions, findings, and conclusions or recommendations expressed in this material are those of the authors and do not necessarily reflect the views of the National Science Foundation.

\section{REFERENCES}

[1] van Aalst, M.K., The impacts of climate change on the risk of natural disasters. Disasters, 30(1), pp. 5-18, 2006. doi:10.1111/j.1467-9523.2006.00303.x

[2] Cutter, S.L., Boruff, B.J. \& Shirley, W., Social vulnerability to environmental hazards. Social Science Quarterly (Blackwell Publishing Limited), 84(2), pp. 242-261, 2003. doi:10.1111/1540-6237.8402002

[3] Lindell, M.K. \& Prater, C.S., Assessing community impacts of natural disasters. Natural Hazards Review, 4(4), pp. 176-185, 2003.doi:10.1061/(ASCE)1527-6988(2003)4:4(176)

[4] Oh, E.H., Deshmukh, A. \& Hastak, M., Risk assessment of critical infrastructure in disaster preparedness and response, Proceedings of the 16th Annual Canadian Construction Research Forum, August 9-11, 2009, Banff, AB, 2009.

[5] Homeland Security and Counterterrorism, The Federal Response to Hurricane Katrina: Lessons Learned, 2006.

[6] Scawthorn, C.F., Flores, P., Blais, N., Seligson, H., Tates, E., Chang, S., Mifflin, E., Thomas, W., Murphy, J., Jones, C. \& Lawrence, M., HAZUS-MH flood loss estimation methodology. II. Damage and loss assessment. Natural Hazards Review, 7(2), pp. 72-81, May 2006. 
[7] Oh, E.H., Identification of the Impact of Critical Infrastructure on Associated Industries: Analysis of a Flood Disaster Event, Master's Thesis, Purdue University, IN, USA, 2008.

[8] Oh, E.H. \& Hastak, M., Impact analysis of natural calamities on infrastructure and industries, Proceedings of the 4th i-REC Conference, April 30-May 2, 2008, Christchurch, New Zealand, 2008.

[9] Hiete, M. \& Merz, M., An indicator framework to assess the vulnerability of industrial sectors against indirect losses, Proceedings of the 6th International ISCRAM Conference, May 2009, Gothenburg, Sweden, 2009.

[10] Deshmukh, A., Severity of Social and Economic Impact due to Flood Damaged Critical Infrastructure on Associated Communities and Industries, Master's Thesis, Purdue University, IN, USA, 2010.

[11] Deshmukh, A., Oh, E.H. \& Hastak, M., A framework to assess the social and economic impacts on communities and industries due to loss in serviceability of infrastructure networks after floods. Proceedings of the 2nd Second International Conference on Flood Recovery Innovation and Risk, 26th-28th May 2010, Milan, Italy, 2010.

[12] Saaty, T.L., Multicriteria Decision Making: the Analytic Hierarchy Process: Planning, Priority Setting Resource Allocation, 2nd edn, RWS Publications, 1990.

[13] Hastak, M.H. \& Shaked, A., ICRAM-1: model for international construction risk assessment. Journal of Management in Engineering, 16(1), pp. 59-69, 2000. doi:10.1061/(ASCE)0742-597X(2000)16:1(59)

[14] Simpson, D.M., Rockaway, T.D., Weigel, T.A., Coomes, P.A. \& Holloman, C.O., Framing a new approach to critical infrastructure modeling and extreme events. International Journal of Critical Infrastructures, 1, pp. 125-143, 2005. doi:10.1504/IJCIS.2005.006115 